\title{
Three different patterns of how low-intensity waves can affect the energy budget of littoral fish: a mesocosm study
}

\author{
Stefan Stoll · Philipp Fischer
}

Received: 28 September 2009/ Accepted: 17 September 2010

(C) Springer-Verlag 2010

\begin{abstract}
In a mesocosm study, somatic and otolith growth of six types of juvenile cyprinids differing in body size and body shape were studied in a low-intensity wave treatment and a no-wave control. Depending on fish type, somatic growth was either reduced by up to $60 \%$ or increased by up to $50 \%$ following exposure to the wave treatment. Somatic growth and otolith daily increment width (ODIW), the latter being used as a proxy for the fish energy turnover, were compared to reveal the effects of waves on the energy budget of the fish. Three different reaction types to waves, which correlated to the body morphology of the six fish groups, could be distinguished. Small and fusiform fish benefitted from low-intensity waves and showed higher somatic growth rates and greater ODIW in the wave treatment. In small, deep-bodied fish, growth and ODIW were reduced by waves. Finally, in larger fish with either a fusiform or deep-bodied shape, ODIW was decoupled from somatic growth, with larger ODIW in waves, but reduced somatic growth. These results
\end{abstract}

Communicated by Craig Osenberg.

S. Stoll · P. Fischer

Limnological Institute, University of Constance,

78457 Constance, Germany

Present Address:

S. Stoll $(\square)$

Department for Limnology and Conservation,

Research Institute Senckenberg, Clamecystr. 12,

63571 Gelnhausen, Germany

e-mail: stefan.stoll@ senckenberg.de

Present Address:

P. Fischer

Alfred-Wegener-Institute for Polar and Marine Research,

Biologische Anstalt Helgoland, Kurpromenade 201,

27498 Helgoland, Germany show that low-intensity hydrodynamic stress is a much more important and complex habitat factor than previously assumed. It is concluded that hydrodynamic stress by waves should be accounted for in bioenergetic models and studies on habitat choice in littoral fish species.

Keywords Hydrodynamic stress - Somatic growth · Otolith daily increment width · Activity costs .

Ship-induced waves

\section{Introduction}

The littoral zone is often described as an essential habitat for lake fish (Werner et al. 1977; Keast 1985; Fischer and Eckmann 1997a, b), with most lake fish species using the littoral zone at least periodically during their life cycle. In Lake Constance, Germany, for example, 32 of the 33 lake fish species use the littoral zone, especially during their early life stages (Fischer and Eckmann 1997b). High species diversity and abundance in the littoral zone have been attributed to its greater habitat and food diversity compared to other lake habitats (Tonn and Magnuson 1982; Pierce 1994; Lewin et al. 2004).

Many studies have investigated the environmental parameters that structure littoral fish communities, with most having focused on static physical habitat characteristics, such as structural complexity (macrophytes, dead wood; Werner et al. 1977; Savino and Stein 1989a, b; Rossier et al. 1996), water depth (Werner et al. 1977; Fischer and Eckmann 1997b), and substratum type (Fischer and Eckmann 1997a; Lewin et al. 2004). Such models, however, often explain only a limited amount of variability in the respective data sets, especially on small spatial and temporal scales (Jackson et al. 2001). 
Parts of the remaining variability may be explained by dynamic environmental variables. For lake shorelines, hydrodynamic stress caused by wind or ship waves is one of the most prominent dynamic variables (Wolter et al. 2004; Hofmann et al. 2008). To date, few studies have examined the effects of waves on the distribution (Lienesch and Matthews 2000), foraging success and growth of littoral fish (Stoll et al. 2008; 2010). Therefore, current knowledge of the mechanisms of how waves affect the energy budget of fish and of which fish traits mediate wave effects is limited.

A fish's energy budget may be both positively (benefit) or negatively (loss) affected by waves. For example, food intake may be altered by waves (Stoll et al. 2010). Studies on the effects of hydrodynamic stress on fish larvae in open water have shown that turbulence increases the prey encounter rate (Rothschild and Osborn 1988). However, at high turbulence levels, prey capture success becomes hampered (MacKenzie et al. 1994), leading to a domeshaped response of fish foraging success to turbulence. In an analogous context, waves in the littoral zone may increase the encounter rate of food items, with benthivorous fish reaping a particular benefit as macroinvertebrates are resuspended by waves (Gabel et al. 2008), which may increase their conspicuity and accessibility to fish.

Activity costs may also be altered by waves (Stoll et al. 2008). The activity costs of lake fishes have long been believed not to be relevant. Thus, in bioenergetic models, such as the Wisconsin Fish model by Hanson et al. (1997), the activity multiplier in most of the parameterizations for lake fish species is set to one. This view has changed over the last two decades, with the results from an increasing number of studies suggesting that the activity costs of fish living in the littoral zone may be not only relevant but also much more variable than previously assumed (Boisclair and Leggett 1989; Rennie et al. 2005). Activity costs depend on swimming speed, turning rate and acceleration (Boisclair and Tang 1993; Krohn and Boisclair 1994), all of which may be significantly increased to cope with turbulence and chaotic current patterns (Enders et al. 2004).

By affecting food intake and costs for activity, waves will ultimately alter the amount of energy available for growth and reproduction, thereby making a certain habitat more or less profitable for fish. As a result, some fish may prefer or avoid shallow water habitats according to amount of actual wave exposure (Lienesch and Matthews 2000). The traits of the fish that mediate their reaction to waves are largely unknown. The energetic costs of swimming and swimming performance depend on fish morphology (Blake 2004; Langerhans 2008). Fulton et al. (2005) successfully related pectoral fin aspect ratios to swimming performance under hydrodynamic stress in labriform-swimming fish. However, in carangiform-swimming fish, which is the most common swimming mode in littoral fishes, pinpointing morphological traits that indicate high swimming performance when exposed to hydrodynamic stress has proven more difficult (Felley 1984).

In some studies, fish body depth has been regarded as such a key morphological trait (Webb 2002). In deepbodied fish, costs for posture control are higher than in other groups (Webb 2002). As a general principle, a larger body size and greater metacentric height lead to greater momentum when subjected to wave action, which in turn increases the need for balance adjustments (Ohlmer 1964; Marchaj 1988; Webb 2002). However, it has also been speculated that a deep-bodied morphology in combination with large fins may dampen yawing, pitching, heaving, and slip disturbances (Webb 2002). Furthermore, a small size may also increase the agility of the fish and thereby increase successful foraging of suspended prey items.

We report here the first study to investigate the effects of a realistic lake littoral wave scenario on the energy budget of littoral fish. We tested six different groups of fish, belonging to two species which are common in littoral zones of Central Europe, namely, the common dace (Leuciscus leuciscus) and the common bream (Abramis brama). Two variables in the energy budget of the fish were assessed: somatic growth rate and otolith daily increment width (ODIW). The latter was used as a proxy for energy turnover. A comparison of these two variables allowed us to make inferences on foraging success of the fish in relation to waves. The growth and ODIW results were then related to the fish traits, species identity, fish size and body shape to explore how waves affect littoral fish.

\section{Materials and methods}

\section{Experimental design and procedures}

The experiment was carried out in two identical outdoor mesocosms with base dimensions of $10 \times 1 \mathrm{~m}$ and a water depth of $0.9 \mathrm{~m}$. In each mesocosm, a 3.5-m-long slope was installed at one end, simulating the shallowest part of the littoral zone of Lake Constance. The slope was constructed using a metal grid, covered by a thick canvas and topped with a 10- to 15-cm-deep layer of gravel and stones. The grain sizes used were $1-2 \mathrm{~cm}$ as a basic coverage with 6- to 20 -cm large stones in between. This substratum is representative of the natural substratum dominating in many eulittoral areas of Upper Lake Constance.

The area with a water depth shallower than $40 \mathrm{~cm}$ was separated from the deeper parts of the mesocosm by a 4-mm knot-to-knot mesh curtain, which confined fish to the shallows while allowing a free exchange of water. Earlier studies have shown that many small and fusiform fish in 
the littoral zone of Lake Constance, among them age-0 dace and bream, significantly prefer the uppermost littoral area $(<40 \mathrm{~cm}$ water depth), while with increasing body length and body depth, dace and bream shift towards deeper littoral habitats (Fischer and Eckmann 1997b).

All experiments were run in parallel in the two identical mesocosm systems. One mesocosm was equipped with an air pressure-driven wave generator, which was installed at the non-sloping end. The second mesocosm served as a no-wave control treatment. The frequency of hydrodynamic disturbance events in the first mesocosm imitated the summer wave regime of a well-studied experimental sampling site used by the Limnological Institute of the University of Constance (known as "Littoral Garden"). This site is a moderately exposed littoral habitat situated about $1-2 \mathrm{~km}$ from the car ferry route connecting the cities of Meersburg and ConstanceStaad on Upper Lake Constance. The normal wave regime at this site, as in many sites at Lake Constance, is a composite of natural, wind-driven waves and artificially pulsed, ship-induced waves, with the latter responsible for about $65-70 \%$ of the total energy flux to the shore from June to August (Hofmann et al. 2008). In order to imitate the routine shuttling of the car ferry and the passage of tourist ships visiting the nearby island of Mainau, the wave generator produced six wave pulses per hour from 0900 to 2000 hours and two wave pulses per hour between 2000 and 0900 hours. Each wave pulse lasted for 2 min. The experimental setup delivered near-harmonic waves with a maximum wave height $H$ of $0.13 \mathrm{~m}$, wave period $T$ of $1.2 \mathrm{~s}$, and a wave number $k$ of $2.8 \mathrm{~m}^{-1}$ at the net curtain and $3.1 \mathrm{~m}^{-1}$ near the surf zone. Maximum near-bottom orbital velocities associated with surface waves, $u_{\max }$, were estimated using linear wave theory (Kundu and Cohen 2002). The resulting $u_{\max }$ was $0.20-0.25 \mathrm{~m} \mathrm{~s}^{-1}$ in the lower part of the fish compartment at a water depth of $0.4 \mathrm{~m}$ and $0.30-0.40 \mathrm{~m} \mathrm{~s}^{-1}$ at a water depth of $0.2 \mathrm{~m}$. These values were comparable to those occurring at the Littoral Garden, where $u_{\max }$ of around 0.3 and $0.4 \mathrm{~m} \mathrm{~s}^{-1}$ are typical in water depths of 0.4 and $0.2 \mathrm{~m}$, respectively (Hofmann 2007).

Energy flux is an appropriate measurement of the ecological relevance of waves (Hofmann et al. 2008). The limited dimensions of the mesocosm required that wave lengths and periods in the experimental setup be shorter than those in the Littoral Garden $(T=1.2$ in the mesocosm vs. $T=2.0-3.3$ for wind and ship waves in the Littoral Garden). With about $20 \mathrm{~W} \mathrm{~m}^{-1}$, the energy flux in the mesocosm was within the range of the typical shippinginduced energy fluxes at the Littoral Garden during the spring and summer (minimum $13 \mathrm{~W} \mathrm{~m}^{-1}$ in March; maximum $31 \mathrm{~W} \mathrm{~m}^{-1}$ in July and August; Hofmann et al. 2008).
The water temperature was measured throughout the experiment with Onset temperature loggers with a resolution of $12 \mathrm{~h}^{-1}$. In each mesocosm, one logger was placed at the water surface and a second at the bottom in the middle of the fish compartment.

The mesocosms were lake-fed flow-through systems in which a complete water exchange was achieved over $24 \mathrm{~h}$. Water was introduced into the mesocosm via the fish compartment and drained via an outlet situated at the opposite end of the mesocosm. To prevent thermal stratification, a physical factor that might severely bias fish behaviour particularly in the no-wave control mesocosm, both mesocosms were slightly aerated in the non-fish compartment using compressed air and limestone diffusers to promote upwelling.

Six groups of juvenile fish, differing with respect to four variables, namely, species, age, body size (fork length and body mass) and body shape (Table 1), were tested for their susceptibility to waves in terms of somatic and otolith growth.

Dace were caught by beach seining in Lake Constance about 1 month before the experiments. Bream were bred at the Limnological Institute of the University of Constance from individual fish caught in Lake Constance. Prior to the experiments, all fish, with the exception of the age-0 bream, were kept in 300-L flow-through lake water tanks at temperatures of $19 \pm 1{ }^{\circ} \mathrm{C}$. Holding conditions for age- 0 bream differed with regard to temperature in order to produce two discrete size groups. One half of the cohort was raised at $23^{\circ} \mathrm{C}$ and therefore grew fast, resulting in the group B0-L, while the other half was raised at $15^{\circ} \mathrm{C}$, resulting in a group of smaller individuals, B0-S (Table 1). Holding conditions of B0-L and B0-S were standardized with those of the other fish groups 1 week prior to the start of experiment.

Until the experiments began, all fish were held indoors under a light regime that matched the natural day-night cycle at latitude $47^{\circ} 40^{\prime} \mathrm{N}$ and fed ad libitum with a diverse diet of living water fleas, dead chironomid larvae and commercial fish flakes.

Fish of all groups except B0-S were marked individually with coded wire tags. Fish $>65 \mathrm{~mm}(\mathrm{~B} 2, \mathrm{D} 1)$ were marked on the right cheek, while smaller fish (B1, B0-L, D0) were marked in the body cavity; in both cases a 24-gauge needle inserted behind the ventral fins at a low angle was used. During the marking procedure, fish were anaesthetized with $0.3 \mathrm{ml} \mathrm{L}^{-1}$ phenoxy-ethanol. No tags were lost during the subsequent experiments.

All fish except those in group B0-S were measured and weighed immediately before the experiment began. Fork length was recorded to the nearest $0.5 \mathrm{~mm}$ and body mass to the nearest $0.01 \mathrm{~g}$. B0-S fish were too small to be marked or measured before the experiment and were thus 
Table 1 Characteristics of the fish groups

\begin{tabular}{lclll}
\hline Fish group $^{\mathrm{a}}$ & $n$ per set & Fork length $^{\mathrm{b}}(\mathrm{mm})$ & Body mass $^{\mathrm{b}}(\mathrm{g})$ & Body shape $^{\mathrm{c}}(\%)$ \\
\hline Bream ac 2 (B2) & 4 & $76.5 \pm 5.9 ; \mathrm{L}$ & $5.94 \pm 1.56 ; \mathrm{L}$ & $28.5 ; \mathrm{d}$ \\
Bream ac 1 (B1) & 10 & $47.6 \pm 5.8 ; \mathrm{S}$ & $1.44 \pm 0.58 ; \mathrm{S}$ & $25.4 ; \mathrm{d}$ \\
Bream ac 0 large (B0-L) & 5 & $55.4 \pm 5.5 ; \mathrm{S}$ & $2.18 \pm 0.57 ; \mathrm{S}$ & $27.5 ; \mathrm{d}$ \\
Bream ac 0 small (B0-S) & 30 & $22.8 \pm 1.5 ; \mathrm{S}$ & $0.14 \pm 0.04 ; \mathrm{S}$ & $19.5 ; \mathrm{f}$ \\
Dace ac 1 (D1) & 10 & $76.1 \pm 8.3 ; \mathrm{L}$ & $4.49 \pm 1.64 ; \mathrm{L}$ & $17.6 ; \mathrm{f}$ \\
Dace ac 0 (D0) & 15 & $43.2 \pm 3.6 ; \mathrm{S}$ & $0.82 \pm 0.23 ; \mathrm{S}$ & $17.6 ; \mathrm{f}$ \\
\hline
\end{tabular}

${ }^{a}$ Bream (Abramis brama) and dace (Leuciscus leuciscus) of different age classes (ac) were used

${ }^{\mathrm{b}}$ Fork length [mean \pm standard deviation (SD)] and body mass (mean $\pm \mathrm{SD}$ ): $L$ large, $S$ small

${ }^{c}$ Body shape is expressed as the percentage ratio of body depth to fork length: $d$ deep-bodied, $f$ fusiform

only weighed. Fork length for B0-S fish at the beginning of the experiments was estimated from a mass-to-length relationship established using sibling fish from the same holding tank (fork length $=38.59 \times\left(\right.$ body mass) ${ }^{0.283}$; $\left.r^{2}=0.87 ; P<0.001\right)$.

Experiments began in the morning with the transfer of one set of fish (Table 1) into the net-enclosed shallow compartment of the wave mesocosm and another set into the no-wave mesocosm. The fish were allowed to acclimate for $6 \mathrm{~h}$, after which the wave regime in the wave-mesocosm was started. Throughout the experiment, fish in both mesocosms were fed daily between 0900 and 1200 hours with $25 \mathrm{~g}$ of living water fleas, $25 \mathrm{~g}$ of dead chironomid larvae and $2 \mathrm{~g}$ of commercial fish flakes. The water fleas were sieved through a 1-mm mesh in order to provide a standard prey size ratio in which $15 \mathrm{~g}$ were smaller than the mesh size and $10 \mathrm{~g}$ were larger than the mesh size. The total quantity of food supplied per day corresponded to approximately $50 \%$ of the total body mass of all fish in a mesocosm. This composition of different food types allowed for benthic, pelagic and surface feeding in all size classes of fish used in the experiment. The preferred feeding mode of the fish used in this study, however, is picking for benthic food items.

The experiments lasted 13 days, after which time all fish were caught with a hand-held dip net and immediately killed with trichlormethyl-propanol $\left(2 \mathrm{~g} \mathrm{~L}^{-1}\right)$. The fork length and body mass of all fish were measured and the fish were stored in $70 \%$ alcohol for further processing. The experiment was replicated three times between 27 July and 6 September 2005.

Laboratory work, data analysis and statistics

Specific growth rates in terms of fork length and body mass were calculated for all individual fish in all experiments, except for the untagged group, B0-S. In this group, individual mass and length increases were estimated by sorting the individual mass values from the start and end of the experiment and match-merging these into most probable value pairs according to their rank order. This procedure assumed that all fish grew in a similar way and that the smallest fish before the experiment was still the smallest fish after the experiment. If any mortality of fish occurred in the mesocosm during the experiment, a corresponding number of individuals was randomly excluded from the start data set in order to standardize the number of values at the start and end of the experiment. This growth estimate method for the B0-S group was validated using the other fish groups, in which each fish was individually recognizable. Their mass and length growth rates were calculated according to the same procedure used for group B0-S (i.e. most probable value pairs from ranking), and the results were compared with the actual growth rates calculated for individuals with the aid of the identification tags. This comparison was performed for a total of ten groups with $n \geq 10$ (B1, D1 and D0), randomly selected from the three replicates of both the wave and control treatments. Average specific growth rates and standard deviations obtained by the rank order procedure never varied from the actual results by more than $2 \%$, thereby validating the method.

In the lab, the coded wire identification tags were extracted and the lapilli of all fish were dissected, rinsed and dried. The right lapillus was embedded in epoxy resin on a microscope slide, ground down to the nucleus and polished. The ODIW were measured under a microscope (Zeiss Axioscope; Carl Zeiss, Jena, Germany) fitted with a camera (Sony AVC 05CE; Sony Corp, Tokyo, Japan) at 400-1,250× magnification, using image analysing software developed by the technical workshop at the University of Constance. Growth increments were assigned to the days of the experiment by allocating the last completely visible increment to the day prior to the end of the experiment and counting backwards from there. Daily increments of each otolith were measured three times by the same observer but on different days, without prior knowledge of previous results. Average values of these triplicate measurements were taken for further analysis. If the ODIW 
varied between replicate measurements by more than $5 \%$, the otoliths were read again. If the new triple replicate measurements also varied by more than $5 \%$, the measurements were discarded; this occurred in five fish individuals. The first day of the experiment was treated as acclimatization time, and thus otolith readings for this day were also discarded.

The daily mean water temperature varied between 12.2 and $19.3{ }^{\circ} \mathrm{C}$ over all three replicates. As the ODIW is dependent on the actual water temperature, all ODIW measurements were standardized to the mean water temperature of $15^{\circ} \mathrm{C}$ throughout the experiments. The temperature correction term was established independently for each of the six fish groups. For this, all ODIW measurements from the no-wave control treatment were fitted against the corresponding daily mean temperature by linear regression. The regression slopes were then used to correct the ODIW values recorded in the six groups. Linear regression was used because it provided the best fits at the small range of temperatures occurring throughout the experiment.

The program JMP4.0 (SAS Institute, Cary, NC) was used for the statistical analyses of the data. All data were analysed by analysis of variance (ANOVA) after having checked for equal variances. Further comparisons between clusters of fish groups (post hoc tests) were achieved using ANOVA contrast analysis and Tukey-HSD tests.

\section{Results}

No mortality was observed during the mesocosm experiments in the fish groups B2, B0-L and D1. In the groups B1, B0-S and D0, 1.6, 16.6 and $11.1 \%$ of fish, respectively, were not re-caught after the experiments and were therefore assumed to have died.

\section{Somatic growth}

Specific growth rates (Fig. 1a, b) were analysed using a full factorial ANOVA model with the independent factors fish group (B2, B1, B0-L, B0-S, D1, D0) and wave treatment (wave, no wave) as fixed factors and replicate $(1,2,3)$ as a random factor. Only fish group, treatment and the interaction term fish group $\times$ treatment significantly contributed to the model explaining length and mass growth of the fish (Table 2a, c). The factor replicate and all interactions containing the factor replicate were not significant and therefore subsequently eliminated.

The significant interaction between fish group and treatment showed that the wave regime affected somatic growth differently in the individual fish groups. The ANOVA contrast analysis based on this interaction term
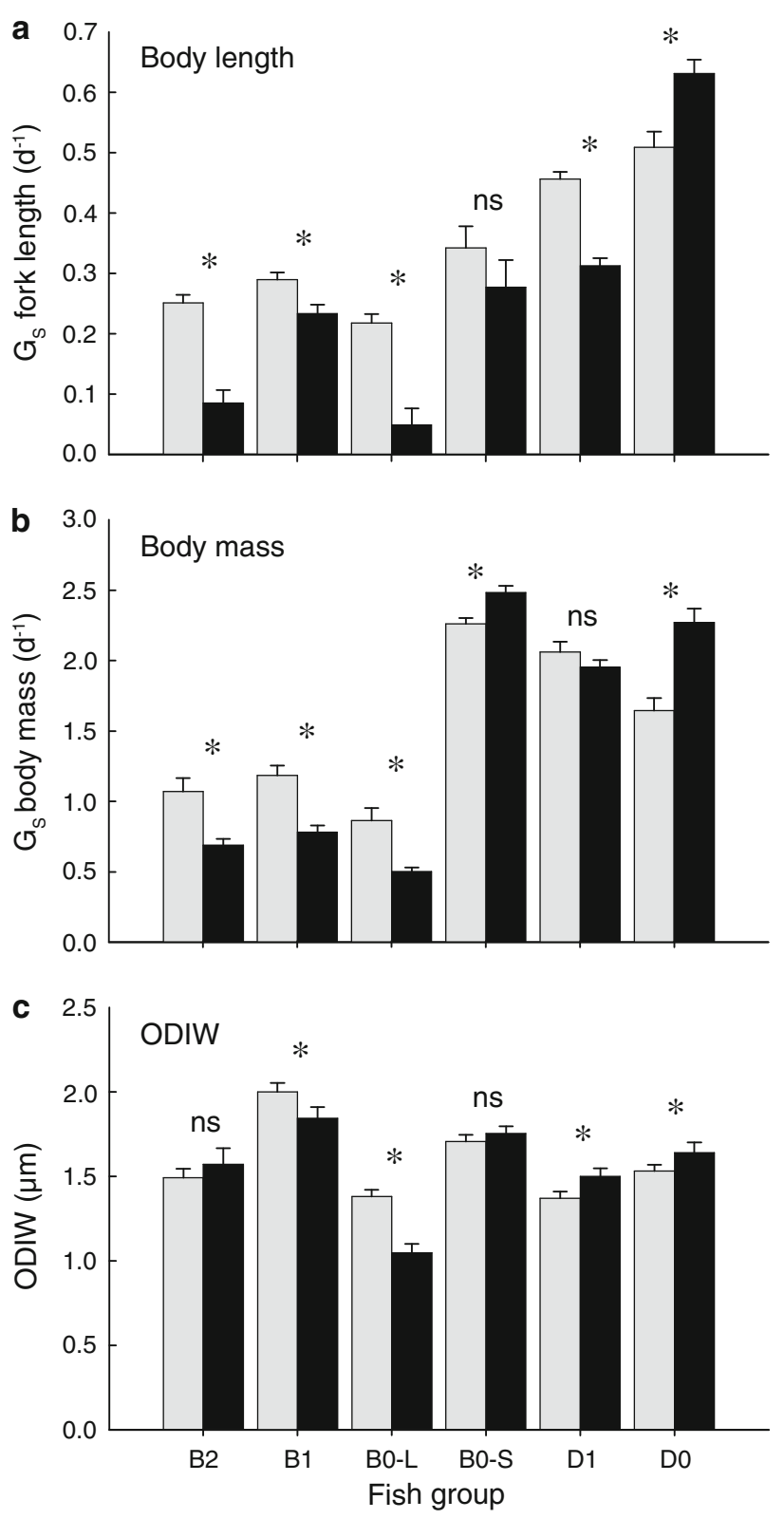

Fig. 1 Specific growth rates $\left(G_{S}\right)$ in terms of body length (a) and body mass (b) and otolith daily increment widths $(O D I W ; \mathbf{c})$ in the control (grey bars) and wave (black bars) treatment for the six fish groups used in the mesocosm experiment: bream age-2 (B2), bream age-1 (B1), bream age-0 large $(B O-L)$, bream age-0 small $(B O-S)$, dace age-1 $(D 1)$ and dace age- $0(D 0)$. Values are the mean \pm standard deviation. For each fish group, differences between wave and control treatment were tested with analysis of variance (ANOVA). ${ }^{*} P<0.05$, $n s$ not significant

was used to compare the wave effects on different species (bream vs. dace), body sizes (small vs. large) and body shapes (fusiform vs. deep-bodied). This analysis revealed that bream were more negatively affected by wave action than dace, with the latter actually benefitting in part from wave action (Table 2, analyses b, d). In contrast, fish size had no overall influence on growth in the wave regime. 
Table 2 Results of ANOVA testing the hypothesis of whether fish species, fish size (length or body mass) or fish body shape can explain the growth differences found between the treatments: analysis of specific fork length (a) and body mass growth rates (c) of individual fish used in the mesocosm experiment and following contrast analysis on the interaction term treatment $\times$ fish group $(b, d)$

\begin{tabular}{|c|c|c|c|c|}
\hline Factor & SS & $d f$ & $F$ & $P$ \\
\hline \multicolumn{5}{|c|}{ a. Fork length—specific growth rate $\left(\right.$ day $\left.^{-1}\right)$} \\
\hline Treatment & 0.4 & 1 & 9.2 & $0.003 *$ \\
\hline Fish group & 6.7 & 5 & 27.9 & $<0.001 *$ \\
\hline Treatment $\times$ fish group & 0.9 & 5 & 3.8 & $0.002 *$ \\
\hline \multicolumn{5}{|c|}{ b. Fork length-specific growth rate $\left(\right.$ day $\left.^{-1}\right)$} \\
\hline Species (bream, dace) & 0.4 & 1 & 7.6 & $0.006 *$ \\
\hline Length/body mass (small, high) & 0.1 & 1 & 0.8 & 0.366 \\
\hline $\begin{array}{l}\text { Body shape (bream age- } 0 \mathrm{~S} \text {, other } \\
\text { groups) }\end{array}$ & 0.3 & 1 & 5.6 & $0.01 \mathrm{c}$ \\
\hline \multicolumn{5}{|c|}{ c. Body mass-specific growth rate $\left(\right.$ day $\left.^{-1}\right)$} \\
\hline Treatment & 0.3 & 1 & 1.0 & 0.318 \\
\hline Fish group & 149.0 & 5 & 92.1 & $<0.001 *$ \\
\hline Treatment $\times$ fish group & 13.3 & 5 & 8.2 & $<0.001^{*}$ \\
\hline \multicolumn{5}{|c|}{ d. Body mass-specific growth rate $\left(\right.$ day $\left.^{-1}\right)$} \\
\hline Species (bream, dace) & 4.0 & 1 & 12.5 & $0.001 *$ \\
\hline Length/body mass (small, high) & 0.6 & 1 & 2.0 & 0.160 \\
\hline $\begin{array}{l}\text { Body shape (bream age- } 0 \mathrm{~S} \text {, other } \\
\text { groups) }\end{array}$ & 4.7 & 1 & 14.6 & $<0.001^{*}$ \\
\hline
\end{tabular}

As there are no deep-bodied dace, only bream were included in the test for effects of body shape

ANOVA Analysis of variance

$* P<0.05$

Body shape was shown to significantly affect mass and the length growth pattern, with deep-bodied fish experiencing a more severe loss of growth in the wave mesocosm than fusiform fish (Table 2, analyses b, d). As no deep-bodied dace exist, this last test only included bream.

\section{Otolith daily growth increments}

Average otolith daily increment widths (Fig. 1c) differed significantly among the six fish groups (Table 3, analysis a). Subsequent ANOVA contrast analysis comparing the factors species, body size and body shape (Table 3, analysis b) revealed that species affiliation had a significant effect on otolith growth, with dace forming wider otolith increments than bream when exposed to waves. Fish size and body shape also had significant effects, with large fish and fusiform fish forming larger increments in the wave treatment than small and deep-bodied fish. Unfortunately, significant interactions, including the factor replicate, were found in the ANOVA analysis. Post-hoc tests revealed that this was due to narrower ODIW in the second replicate compared to the first and third replicates for D0 in the wave treatment (Tukey-HSD $q=3.89, P<0.05$ ). To accommodate this,
Table 3 Results of the ANOVA analysis testing the hypothesis of whether fish species, fish size (length or body mass) or fish body shape can explain the growth differences found between the treatments: analysis of otolith daily increment widths of individual fish in the mesocosm experiment (a) and following contrast analysis on the interaction term treatment $\times$ fish group $\times$ replicate $(b)$

\begin{tabular}{|c|c|c|c|c|}
\hline Factor & SS & $d f$ & $F$ & $P$ \\
\hline \multicolumn{5}{|l|}{ a. Otolith ring width $(\mu \mathrm{m})$} \\
\hline Treatment & 0.05 & 1 & 1.0 & 0.417 \\
\hline Fish group & 13.3 & 5 & 7.0 & $0.005 *$ \\
\hline Treatment $\times$ fish group & 1.50 & 5 & 3.2 & 0.054 \\
\hline Replicate & 0.95 & 2 & 1.6 & 0.267 \\
\hline Treatment $\times$ replicate & 0.09 & 2 & 0.5 & 0.607 \\
\hline Fish group $\times$ replicate & 3.79 & 10 & 4.0 & $0.018 *$ \\
\hline $\begin{array}{l}\text { Treatment } \times \text { fish group } \times \text { replicate } \\
\text { b. Otolith ring width }(\mu \mathrm{m})\end{array}$ & 0.93 & 10 & 2.2 & $0.021 *$ \\
\hline Species (bream, dace) & 0.65 & 1 & 15.1 & $<0.001 *$ \\
\hline Length/body mass (small, large) & 0.43 & 1 & 10.0 & $0.002 *$ \\
\hline $\begin{array}{l}\text { Body shape (bream age- } 0 \mathrm{~S} \text {, other } \\
\text { groups) }\end{array}$ & 0.51 & 1 & 11.9 & $0.001 *$ \\
\hline
\end{tabular}

As there are no deep-bodied dace, only bream were included in the test for effects of body shape

$* P<0.05$

ANOVA contrast analyses were based on the interaction term fish group $\times$ treatment $\times$ replicate. The results, however, were the same as those based on the term fish group $\times$ treatment alone, indicating that the replicate effect was minor compared to the effects of species, body size and body shape.

To compare gains and losses in somatic and otolith growth caused by waves, percentage differences in somatic and otolith growth between the wave and no-wave treatments were calculated for all fish groups (Fig. 2). For each fish group, one-way ANOVA with the factor treatment was used to test for differences in length and weight specific growth rates as well as ODIW between the wave and control treatment. Three different patterns emerged. The first one comprised D0 and B0-S (both small and fusiform), which showed an increase in both ODIW and somatic growth in the wave treatment. In B0-S, significant differences were recorded in mass growth but not in length growth, and only ODIW differences showed a strong trend $(P=0.12)$. The second pattern comprised B1 and B0-L (both small and deep-bodied), which experienced a significant decrease in both ODIW and somatic growth when exposed to waves. In B2 and D1 (both large, but differing in body shape), finally, ODIW increased, but somatic growth decreased in the wave treatment. Mass growth differences in D1 and ODIW differences in B2 thus marginally failed to reach significant levels $(P=0.07$ and $P=0.08$, respectively). 

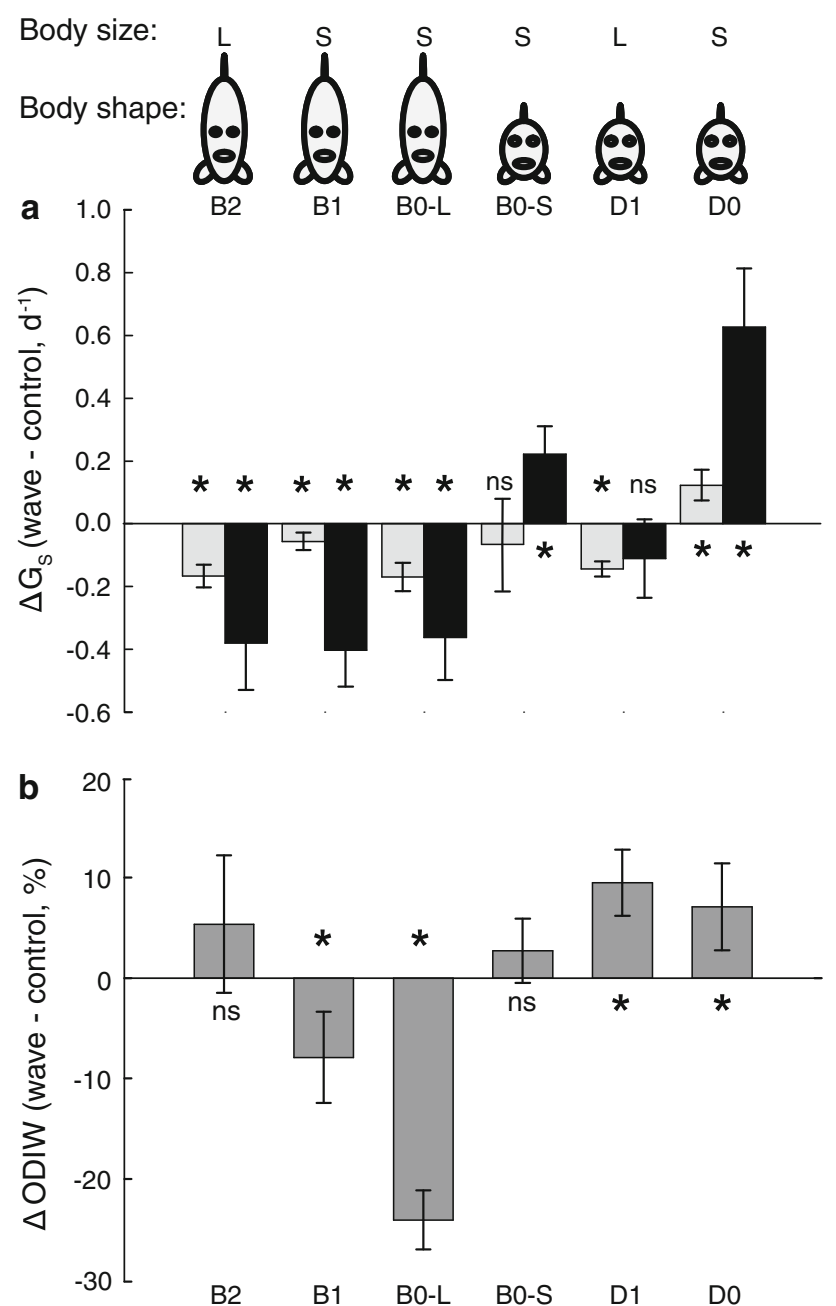

Fig. 2 a Differences in specific growth rate of length (grey bars) and body mass (black bars) between the wave mesocosm and the nonwave control (wave minus control) for the six fish groups (see Fig. 1) used in the mesocosm experiment. b Percentage difference in otolith increment widths between the wave mesocosm and the non-wave control. For each fish group, differences between wave and control treatment were tested with ANOVA. Values are given as the mean \pm standard error. $* P<0.05$, $n s$ not significant. The pictograms give the body shape of each fish group; body sizes are designated as large $(L)$ or small $(S)$

\section{Discussion}

With the exception of studies demonstrating the complete exclusion of fish from a habitat by hydrodynamic stress (Wolter and Arlinghaus 2003), little is known about the less dramatic effects of wave action on freshwater fish. The results of our study show that low-intensity waves have a major impact on the energy budget of juvenile cyprinids. Following exposure to the wave treatment, somatic growth was reduced by up to $60 \%$ in some fish groups while it increased by as much as $50 \%$ in others. These results demonstrate that surface waves are a key environmental factor in the littoral zone, even at low intensities.
In stream ecology, it is generally recognized that hydrodynamic stress affects food uptake and activity costs in fish (Liao 2007; Blanchet 2008). In lake ecology, this has not been demonstrated to date. However, stream currents differ substantially in character from lake waves. Currents are directional, on which chaotic vortical flows may be superimposed. Organisms can orientate themselves to the direction of the flow. In waves, by contrast, this kind of orientation is not possible, as the movement of water is orbital, with perfect systems providing no net water transport in any direction, although in reality background currents and Stokes drift (Monismith and Fong 2004) may occur. The typical pattern of occurrence of waves is also more heterogeneous than that of currents. Ship waves in particular may occur at unpredictable times, and waves breaking in the shallow parts of the littoral zone may create sudden turbulent water movements on a large scale. Organisms that are not alert may be washed ashore by an unexpected wave event.

Our ANOVA contrast analysis of both somatic and otolith growth indicated that dace are generally better adapted to withstand wave-induced hydrodynamic stress than bream. This is in agreement with the more rheophilic lifestyle of dace compared to the largely limnophilic bream (Kottelat and Freyhof 2007). In our study, the growth of the deep-bodied bream was depressed by a low-intensity wave regime, while fusiform individuals profited from waves. This result supports the assumption that body depth may be a key morphological trait to predict the reaction of fish to hydrodynamic stress (Webb 2002). Size, in contrast, did not provoke a clear-cut reaction in the fish groups tested, as small fish either profited (D0, B0-S; small fusiform) or lost (B0-L and B1; small deep-bodied) when subjected to lowintensity waves. However, the current study was limited to a small set of closely related fish groups. Additional studies with more distantly related fish groups of different body shapes are necessary to approve the general applicability of these results.

The growth differences between fusiform and deepbodied bream in relation to waves also explain the habitat shift of bream from the shallow littoral zone to deeper sublittoral zones in the middle of their first summer, which was observed by Fischer and Eckmann (1997b) in Lake Constance. Our experimental results support the argumentation of the latter study as well as that of Stoll et al. (2008) who suggest that with changing body morphology from fusiform to deep-bodied in the middle of the first summer, the trade-off between foraging success and activity costs associated with waves in the shallow water changes for the worse, resulting in bream moving to the calmer sublittoral zone. Dace also gradually move to deeper water habitats as they grow, but they move later and without such a distinct shift, as observed with the bream 
(Fischer and Eckmann 1997b; Stoll et al. 2008), reflecting the decreased profitability of shallow water habitats for fish with increasing body size.

While regularly occurring ontogenetic, seasonal or diel habitat changes are well studied (Werner and Hall 1988; Gliwicz and Jachner 1992; Fischer and Eckmann 1997a), very little is known about non-regular and dynamic drivers of habitat choice in fish (Jackson et al. 2001). Lienesch and Matthews (2000) analysed daily fish abundances in the littoral zone of Lake Texoma, USA and demonstrated that abundances of some fish species correlated with wave height; however, they did not search for traits explaining the preference or avoidance of wave-exposed habitats. Stoll et al. (2010) showed that moderate wave exposure enhanced the feeding success of wild small and fusiform dace and perch (Perca fluviatilis) in Lake Constance. In sedentary perch, different foraging success in relation to wave exposure resulted in different growth rates of local perch populations. Dace, however, proved to be more mobile, such that no growth differences between the open local populations at sites with different wave exposures became apparent. In our mesocosm study, growth in relation to wave exposure was examined in a closed population, with the aim of also resolving growth effects in dace. While mesocosm studies with closed populations and fixed treatments are very helpful for exploring the effects of an environmental variable on a mechanistic level, one has to bear in mind that in the artificial mesocosm environment, quantification of the effects is sometimes difficult. In situ, fish are known to switch between different habitats, trading off on local costs and benefits (Neverman and Wurtsbaugh 1994; Sims et al. 2006). Thus, it is possible that some fish profit from resuspended food, but limit their losses by avoiding wave-exposed habitats when not foraging. For such fishes, enclosure experiments overestimate the growth losses due to moderate waves.

ODIW reflect the energy turnover of a fish (Mosegaard et al. 1988; Yamamoto et al. 1998; Wright et al. 2001). Larger ODIW may be achieved by a higher food uptake (Barber and Jenkins 2001; Armstrong et al. 2004) or by an increase in metabolic rate (Wright 1991; Huuskonen and Karjalainen 1998), such as that prompted by the need to spend more energy on activity. Smaller ODIW, on the other hand, may be the result of a reduced food uptake or a decrease in activity costs. Thus, by contrasting ODIW and the actually realized somatic growth of the fish in the wave treatment and in the no-wave control, we were able to obtain insight into the energy allocation of different fish groups. Even though a few results failed to reach the significance level, three distinct patterns were observed in the effects of waves on fish. These patterns correlated with the body morphology of the six fish groups investigated in this study.
B0-S and D0, both small and fusiform fish, showed larger ODIW and higher somatic growth rates when exposed to the wave treatment. This result suggests that the increase in metabolic rate was due to a higher energy intake, i.e. feeding success, in the wave treatment. Waves can resuspend food items, making them more accessible to agile foraging fish (Lienesch and Matthews 2000) if the turbidity is not too high (Ljunggren and Sandström 2007). With a higher encounter probability, these fish had to invest less energy per prey in foraging, making foraging in the wave treatment more profitable for the fish. The additional amount of energy needed for balancing adjustments for posture control in the wave treatment should have been comparatively low in small and fusiform fish with short body axes and low metacentric heights (Ohlmer 1964; Marchaj 1988).

The small and deep-bodied fish in groups B1 and B0-L incurred both narrower ODIW and reduced somatic growth in the wave treatment compared to the control. The narrower ODIW indicate a reduced feeding success in the wave treatment, suggesting that fish of this reaction type did not profit from resuspended food items. This was confirmed by Gabel et al. (in press). Being small and deepbodied, hydrodynamic stress should be more demanding for them (Ohlmer 1964; Marchaj 1988), so the level of attention available to find food items should be decreased and, at the same time, the amount of energy required for posture control should be increased (Webb 2002). Subsequently, these fish suffered growth losses when exposed to a low-intensity wave regime.

The larger, fusiform or deep-bodied fish in the groups B2 and D1 achieved greater ODIW in the wave treatment than in the no-wave control, signalling an increased metabolic turnover. Being larger and stronger swimmers, these fish must have profited from the higher encounter probability with suspended food compared to the no-wave control and were able to increase their consumption. It has been shown in flow tank experiments that larger fish can maintain foraging at higher levels of hydrodynamic stress (Flore and Keckeis 1998). However, their somatic growth decreased in the wave treatment. Thus, the energy gains must have been counteracted by a strong increase in activity costs in the pulsed wave treatment. The longer body axis and greater metacentric heights of these fish entail a greater momentum in this type of wave action, thereby increasing the need for balancing adjustments (Ohlmer 1964; Marchaj 1988). Alternatively, these fish might also swim faster in order to stabilize their posture (Webb 2002). It has been shown in a wild fish population that increased foraging success can be overcompensated by an even higher amount of energy for activity, leading to slower growth in the fish that feed more (Rennie et al. 2005). 
To test the predictions with regards to foraging success and activity costs that were made based on the ODIW and somatic growth results in this study, our group performed a second study (Gabel et al. in press). This second study fully confirmed the mechanisms that were proposed to explain the ODIW and somatic growth patterns. Using the same wave treatment, we confirmed that small fusiform fish greatly increased their feeding success, but not their activity level. Foraging success was increased in large fish, but in addition, their activity level increased dramatically. Foraging success of small and deep-bodied fish decreased, and these fish showed flight behaviour as soon as a wave pulse terminated.

The results of our study reveal that low-intensity, waveinduced hydrodynamic stress can have significant longterm effects on the growth and metabolic rate of fish. As the energy fluxes achieved in natural habitats can even be much higher than those created in this mesocosm experiment, we assume that their effects are even more severe, resulting in further growth losses in those fish groups that did not even benefit from the low-intensity wave treatment in this study. Furthermore, the fish groups that profited from low-intensity waves may be hampered if hydrodynamic stress exceeds an upper threshold for profitability (MacKenzie et al. 1994; Stoll et al. 2008). Therefore, there is a need to further examine the foraging economics of fish in the littoral zone of lakes in relation to hydrodynamic stress by waves. Open questions include how different levels of waves alter the profitability of foraging for different food types. These results would be most pertinent in terms of understanding how fluctuations in wave action mediate the habitat profitability for fish, the competition between species, and thus the habitat choice of littoral fish.

Acknowledgments We thank J. Koeritzer, A. Meriac, T. Merz, O. Okle, M. Schmid and M. Wolf for help during the mesocosm experiment and lab work and P. Hirsch and H. Hofmann for fruitful discussions. R. Eckmann and W. N. Probst provided valuable comments on earlier versions of this manuscript. This study was completed within the Collaborative Research Centre 454 "Littoral Zone of Lake Constance" and was financially supported by the German Research Foundation (DFG) and a personal grant to S.S. by the German National Academic Foundation. The experiments comply with the current laws of Germany, where this study was performed.

\section{References}

Armstrong JD, Fallon-Cousins PS, Wright PJ (2004) The relationship between specific dynamic action and otolith growth in pike. J Fish Biol 64:739-749

Barber MC, Jenkins GP (2001) Differential effects of food and temperature lead to decoupling of short-term otolith and somatic growth rates in juvenile King George whiting. J Fish Biol 58:1320-1330

Blake RW (2004) Fish functional design and swimming performance. J Fish Biol 65:1193-1222
Blanchet SG (2008) Competition, predation, and flow rate as mediator of direct and indirect effects in a stream food web. Oecologia 157:93-104

Boisclair D, Leggett WC (1989) The importance of activity in bioenergetics models applied to actively foraging fishes. Can J Fish Aquat Sci 46:1859-1867

Boisclair D, Tang M (1993) Empirical analysis of the influence of swimming pattern on the net energetic cost of swimming in fishes. J Fish Biol 42:169-183

Enders EC, Boisclair D, Roy AG (2004) The costs of habitat utilization of wild, farmed, and domesticated juvenile Atlantic salmon (Salmo salar). Can J Fish Aquat Sci 61:2302-2313

Felley JD (1984) Multivariate identification of morphologicalenvironmental relationships within cyprinidae (Pisces). Copeia 1984:442-455

Fischer P, Eckmann R (1997a) Seasonal changes in fish abundance, biomass and species richness in the littoral zone of a large European lake, Lake Constance, Germany. Arch Hydrobiol 139:433-448

Fischer P, Eckmann R (1997b) Spatial distribution of littoral fish species in a large European lake, Lake Constance, Germany. Arch Hydrobiol 140:91-116

Flore L, Keckeis H (1998) The effect of water current on foraging behaviour of the rheophilic cyprinid Chondrostoma nasus (L.) during ontogeny: evidence of a trade-off between energetic gain and swimming costs. Regul Rivers Res Mgmt 14:141-154

Fulton CJ, Bellwood DR, Wainwright PC (2005) Wave energy and swimming performance shape coral reef fish assemblages. Proc R Soc B 272:827-832

Gabel F, Garcia X-F, Brauns M, Sukhodolov A, Leszinski M, Pusch MT (2008) Resistance to ship-induced waves of benthic invertebrates in various littoral habitats. Freshw Biol 53:1567-1578

Gabel F, Stoll S, Fischer P, Pusch MT, Garcia X-F (in press) Differential effects of wind and ship waves on predator-prey interactions between fish and benthic invertebrates: an experimental study. Oecologia

Gliwicz ZM, Jachner A (1992) Diel migrations of juvenile fish: a ghost of predation past or present? Arch Hydrobiol 124:385-410

Hanson PC, Johnson TB, Schindler DE, Kitchell JF (1997) Fish Bioenergetics 3.0 for Windows. University of Wisconsin, Sea Grant Institute, Madison

Hofmann H (2007) Characteristics and implications of surface gravity waves in the littoral zone of a large lake (Lake Constance). $\mathrm{PhD}$ thesis. University of Constance, Constance

Hofmann H, Lorke A, Peeters F (2008) The relative importance of wind and ship waves in the littoral zone of a large lake. Limnol Oceanogr 53:368-380

Huuskonen H, Karjalainen J (1998) A preliminary study on the relationships between otolith increment width, metabolic rate and growth in juvenile whitefish (Coregonus lavaretus L.). Arch Hydrobiol 142:371-383

Jackson DA, Peres-Neto PR, Olden JD (2001) What controls who is where in freshwater fish communities-the role of biotic, abiotic, and spatial factors. Can J Fish Aquat Sci 58:157-170

Keast A (1985) Development of dietary specializations in summer community of juvenile fishes. Environ Biol Fishes 13:211-224

Kottelat M, Freyhof J (2007) Handbook of European freshwater fishes. Publications Kottelat, Cornol

Krohn MM, Boisclair D (1994) Use of a stereo-video system to estimate the energy expenditure of free-swimming fish. Can J Fish Aquat Sci 51:1119-1127

Kundu PK, Cohen IM (2002) Fluid mechanics, 2nd edn. Academic Press, London

Langerhans RB (2008) Predictability of phenotypic differentiation across flow regimes in fishes. Integr Comp Biol 48:750-768 
Lewin W-C, Okun N, Mehner T (2004) Determinants of the distribution of juvenile fish in the littoral area of a shallow lake. Freshw Biol 49:410-424

Liao JC (2007) A review of fish swimming mechanics and behaviour in altered flows. Phil Trans R Soc B 362:1973-1993

Lienesch PW, Matthews WJ (2000) Daily fish and zooplankton abundances in the littoral zone of Lake Texoma, OklahomaTexas, in relation to abiotic variables. Environ Biol Fishes 59:271-283

Ljunggren L, Sandström A (2007) Influence of visual conditions on the foraging and growth of juvenile fishes with dissimilar sensory physiology. J Fish Biol 70:1319-1334

MacKenzie BR, Miller TJ, Cyr S, Leggett WC (1994) Evidence for a dome-shaped relationship between turbulence and larval fish ingestion rates. Limnol Oceanogr 39:1790-1799

Marchaj CA (1988) Aero-hydrodynamics of sailing. International Marine Publ, Camden

Monismith SG, Fong DA (2004) A note on the potential transport of scalars and organisms by surface waves. Limnol Oceanogr 49:1214-1217

Mosegaard H, Svedäng H, Taberman K (1988) Uncoupling of somatic and otolith growth rates in Arctic char (Salvelinus alpinus) as an effect of differences in temperature response. Can J Fish Aquat Sci 45:1514-1524

Neverman D, Wurtsbaugh WA (1994) The thermoregulatory function of diel vertical migration for a juvenile fish, Cottus extensus. Oecologia 98:247-256

Ohlmer W (1964) Untersuchungen über die Beziehungen zwischen Körperform und Bewegungsmedium bei Fischen aus stehenden Binnengewässern. Zool Jahrb Anat 81:151-240

Pierce CL (1994) Littoral fish communities in Southern Quebec lakes: relationship with limnological and prey resource variables. Can J Fish Aquat Sci 51:1128-1138

Rennie MD, Collins NC, Shuter BJ, Rajotte JW, Couture P (2005) A comparison of methods for estimating activity costs of wild fish populations: more active fish observed to grow slower. Can J Fish Aquat Sci 62:767-780

Rossier O, Castella E, Lachavanne J-B (1996) Influence of submerged aquatic vegetation on size class distribution of perch (Perca fluviatilis) and roach (Rutilus rutilus) in the littoral zone of Lake Geneva (Switzerland). Aquat Sci 58:1-14

Rothschild BJ, Osborn TR (1988) Small-scale turbulence and plankton contact rates. J Plankton Res 10:465-474
Savino JF, Stein RA (1989a) Behaviour of fish predators and their prey: habitat choice between open water and dense vegetation. Environ Biol Fish 24:287-293

Savino JF, Stein RA (1989b) Behavioural interactions between fish predators and their prey: effects of plant density. Anim Behav 37:311-321

Sims DW, Wearmouth VJ, Southall EJ, Hill JM, Moore P, Rawlinson K, Hutchinson N, Budd GC, Righton D, Metcalfe JD, Nash JP, Morritt D (2006) Hunt warm, rest cool: bioenergetic strategy underlying diel vertical migration of a benthic shark. J Anim Ecol 75:176-190

Stoll S, Fischer P, Klahold P, Scheifhacken N, Hofmann H, Rothhaupt K-O (2008) Effects of water depth and hydrodynamics on the growth and distribution of juvenile cyprinids in the littoral zone of a large pre-alpine lake. J Fish Biol 72:1001-1022

Stoll S, Hofmann H, Fischer P (2010) Effect of wave exposure dynamics on gut content mass and growth of young-of-the-year fishes in the littoral zone of lakes. J Fish Biol 76:1714-1728

Tonn WM, Magnuson JJ (1982) Patterns in the species composition and richness of fish assemblages in northern Wisconsin lakes. Ecology 63:1149-1166

Webb PW (2002) Control of posture, depth, and swimming trajectories of fishes. Int Comp Biol 42:94-101

Werner EE, Hall DJ (1988) Ontogenetic habitat shifts in bluegill: the foraging rate-predation risk trade-off. Ecology 69:1352-1366

Werner EE, Hall DJ, Laughlin DR, Wagner DJ, Wilsmann LA, Funk FC (1977) Habitat partitioning in a freshwater community. J Fish Res Board Can 34:360-370

Wolter C, Arlinghaus R (2003) Navigation impacts on freshwater fish assemblages: the ecological relevance of swimming performance. Rev Fish Biol Fish 13:63-89

Wolter C, Arlinghaus R, Sukhodolov A, Engelhardt C (2004) A model of navigation-induced currents in inland waterways and implications for juvenile fish displacement. Env Mgmnt 34:656-668

Wright PJ (1991) The influence of metabolic rate on otolith increment width in Atlantic salmon parr, Salmo salar L. J Fish Biol 38:929-933

Wright PJ, Fallon-Cousins P, Armstrong JD (2001) The relationship between accretion and resting metabolic rate in juvenile Atlantic salmon during a change in temperature. J Fish Biol 59:657-666

Yamamoto T, Ueda H, Higashi S (1998) Correlation among dominance status, metabolic rate and otolith size in masu salmon. J Fish Biol 52:281-290 